\title{
EFFECTS OF COMMUNICATION TASKS ON THE GRAMMATICAL RELATIONS MARKED BY SECOND LANGUAGE LEARNERS
}

\author{
JONATHAN NEWTON and GRAEME KENNEDY
}

\author{
Victoria University of Wellington, English Language Institute, P.O. Box 600, \\ Wellington, New Zealand
}

\begin{abstract}
This study reports some possible grammatical consequences of interaction in split and shared information tasks undertaken by adult second language learners of English. Based on an analysis of a learners' corpus of almost 30,000 words, the study examines the morpho-syntax of task-based interaction and, in particular, ways of marking relationships between lexicalized concepts and between clauses by means of prepositions and conjunctions, respectively. The study confirmed the main hypothesis that shared information tasks would result in the use of more coordinating and subordinating conjunctions than split information tasks. The paper suggests that both cognitive and pragmatic reasons may explain why inter-propositional relationships are marked more frequently than intra-propositional relationships in the corpus, and why the marking of inter-propositional relationships may be encouraged more by shared information tasks an by split information tasks. The results of the study suggest that communication tasks for language learning can be designed to influence the use of particular linguistic structures. Copyright (C) 1996 Elsevier Science Ltd
\end{abstract}

\section{INTRODUCTION}

The present study was undertaken to consider the grammatical consequences of task types among second language learners of English. Language learning tasks feature prominently in recent work in both second language acquisition (SLA) research and in pedagogy (Crookes and Gass, 1993a and b). Tasks are seen to represent both the goal of learning (using the language to communicate successfully), and the means to achieve that goal (the appropriate classroom activity-Nunan, 1989: p. 13). This fusing of what are traditionally separate aspects of curriculum design has led some writers in the field to suggest that tasks are a useful planning tool in programme design (Nunan, 1989; Candlin and Murphy, 1987; Prabhu, 1987), possibly making a distinction between syllabus and methodology redundant (Long, 1989). 
The notion of task is a focus for research in a number of disciplines within the human sciences including psychology (e.g. Hancock, 1987) and education (e.g. Cohen, 1986). In SLA studies, experimentally-controlled performances of tasks provide information on the way the interactive behaviour of learners in different task arrangements might facilitate language acquisition. Tasks are claimed to provide opportunities for the negotiation of meaning through which learners clarify unfamiliar input (Pica et al., 1987) and receive feedback on the comprehensibility (though not necessarily the accuracy) of their output (Pica et al., 1989; Swain, 1985) thus "stretching learners interlanguage...pushing them to operate at the outer limits of their current abilities" (Long, 1989: p. 17). Seen in this way, the task is capable of linking what is actually prescribed in the classroom with claims made for the role of meaning-based interaction in SLA as well as with the desired goal of many language learners - to use the language effectively in communication (Long and Crookes, 1991; Long, 1989). These links represent a convergence of interests including those of the learner, the teacher and the researcher. It has been argued that more structurally-based syllabuses on the other hand prescribe units and systems for grading these units that bear little relationship to what we know of the content and progression of language acquisition (Crookes, 1986: pp. 19-22), or with authentic communication.

Specifically, the present study examines the effect of task type and topic on the marking of relationships between lexicalized concepts by means of prepositions, and between clauses by means of conjunctions as evidence, respectively, of the expression of intraand inter-clausal coherence (Givón, 1990a: p. 827). The use of prepositions and conjunctions was the focus of the study because they are frequent in that they make up about $20 \%$ of all the words used by adult native speakers of English and they serve an important function as part of the linguistic mortar which helps the elements of sentences to bond together. Thus, for example the relationship between the concepts rotweiler and bedroom is significantly different in "the rotweiler is in my bedroom" and "the rotweiler is outside my bedroom". Similarly, "I'll stay at home if I feel unwell" and "I'll stay at home because I feel unwell" have a different relationship between the two propositions in each sentence. Brown (1990) has shown that spatial expressions (which are frequently marked by prepositions such as at, in, under, etc.) tend to be incompletely or inaccurately processed, particularly by academically less successful students. Practising language teachers have repeatedly noted that prepositions and some conjunctions are often particularly difficult for learners of English (e.g. Celce-Murcia and LarsenFreeman, 1983).

Various instructional options such as rule-based explanations, drills, and form-focused exercises are available to teachers for guiding learners in the use of prepositions and conjunctions. In addition, learners are likely to need wide-ranging opportunities to use these items in meaningful communication. In the language classroom, such opportunities are commonly met in communication tasks involving meaningful fluency practice with learners "comprehending, manipulating, producing, or interacting in the target language while their attention is principally focused on meaning rather than on form" (Nunan, 1989: p. 10 ). This emphasis on meaning suggests the commonly held view that communication tasks provide teachers with little control over the forms learners use to express their meanings. Various syntheses of task-based methodology and grammar instruction show otherwise. 
Perhaps the most widely practised synthesis is achieved through tasks which require learners to use certain grammatical structures, rules, vocabulary or discourse conventions in the process of achieving a communicative goal but without necessarily requiring learners to attend to the rules or structural properties of the language involved. The approach taken for example by Ur (1988: p. 9), presents tasks which "stress the comprehension of meanings for a non-linguistic purpose while keeping an eye, as it were, on the way the structures are being manipulated in the process". The aim is to consolidate learning through "induc(ing) learners to engage with an item as many times as possible" (Ur, 1988: p. 12). The targeted rules of use and grammatical structures are either assumed knowledge or are learned beforehand through formal instruction.

In a more narrowly focused proposal for integrating task-based language teaching and grammar teaching, Loschky and Bley-Vroman propose the use of structurebased communication tasks in which "structural accuracy in comprehension and production should be made essential to meaning in the task" and "communicativelyorientated feedback on accuracy should be incorporated into the design of the task" (1993: pp. 132-133), though without requiring learners to make decisions solely on grammatical correctness. They argue that when a task requires learners to resolve communication problems which are contingent on grammatical accuracy, the process involves confirming and disconfirming of interlanguage (IL) hypotheses which in turn may lead to language development through restructuring and automatization. They suggest that the key to this process lies in ensuring the task-essentialness of items so that learners are not able to draw on avoidance or communication strategies to work around gaps in their IL as revealed by the tasks. Loschky and Bley-Vroman qualify the claim for restructuring and automatization by suggesting that "conversely, production tasks should be relatively less valuable as chances for learners to notice gaps in their IL hypotheses about the specified structure" (1993: p. 141). We would argue, however, that opportunities for restructuring and acquisition are created through exposure to the target language in the content of the task worksheets, the teacher's instructions, pre-teaching, and through the requirement to be comprehensible in the process of negotiation.

A more overtly grammar-focused proposal suggested by Fotos and Ellis (1991) involves "grammar consciousness-raising tasks". The tasks used by the authors in an experimental study involving groups of Japanese learners of English required the learners to exchange information and negotiate meanings which illustrated a particular grammatical rule concerning dative verbs. Though the rule itself was not provided, the task required the learners to make grammatical judgements based on the rule. The learners made significant gains on successive grammatical judgement tests which assessed their ability to apply rules for placement of direct and indirect objects (though it should be noted that the gains were less than those for learners in comparison groups who had instruction on the dative verbs in a teacher-fronted lesson). The authors argue that the results provide evidence that consciousness-raising tasks can facilitate the learning of explicit grammatical rules. Through these tasks, the learners had opportunities to acquire implicit knowledge in two ways: through meaningful communication and negotiation; and indirectly through "explicit knowledge of L2 rules which will facilitate the acquisition of implicit knowledge" (Fotos and Ellis, 1991: p. 622). 


\section{SPLIT AND SHAKED INFORMATION TASKS}

In a study which provides a useful point of departure for the present study, Doughty and Pica (1986) examined the amount of negotiation of meaning produced by learners doing tasks in which information exchange was either a required or optional feature of task design. They found more negotiation and more repetition in tasks which required information exchange than in tasks in which information exchange was optional, a result attributed to the presence of an information gap in the former type of task. The required/optional distinction is sometimes used synonymously with Long's one-way/twoway distinction (e.g. Ellis, 1991: p. 182; Long, 1989: p. 14). But while both one-way and two-way tasks contain an information gap this is not so for the required/optional distinction. In one-way tasks one person holds all the information while in two-way tasks all have an equal but partial share of information which they must exchange in order to get all the information. In contrast, required information exchange tasks always have an information gap (either one-way or two-way) and optional information exchange tasks do not. The latter are synonymous with decision-making or ranking tasks.

The required/optional distinction is the basis of the task types discussed in the present study, although because of the possible terminology confusion noted above, it will be referred to as a distinction between split and shared information tasks (Nation and Thomas, 1988). The split/shared distinction is also preferred since the way in which information is distributed among participants (i.e. whether it is split equally among group members or shared by all) is the key factor determining the optionality of interaction and is therefore a more fundamental distinction to make.

\section{COMMUNICATION TASKS AND GENRE}

In seeking to describe the generic properties of interaction under various task conditions, the principles of genre analysis provide a useful starting point. Such analysis highlights the relationship between the structural or formal properties of a piece of text and the communicative purpose of that text (Eggins, 1994; Swales, 1990; Martin, 1984). Inasmuch as this relationship holds, different texts written for similar purposes display common properties and so are considered representative of a genre. While genre analysis has been applied to written texts and especially to the teaching of writing in schools, the process of generalizing from purpose to text structure may also improve our understanding of the different modes of spoken discourse typical of certain communication tasks. As with written genre, we would argue that the discourse produced through a task is given its identifiable shape and structure by the communicative purpose of the task. Given this purpose, it is possible to predict the likelihood of the linguistic and discourse features in the ensuing interaction.

The two task types used in the present study, split and shared information tasks, represent two distinct genres. In split information tasks, the purpose is typically for interlocutors to exchange information with each other in order to complete, correct or compare a task worksheet. They thus typically work within a descriptive discourse mode. The genre of description as represented in children's writing in particular has been shown to contain 
linguistic features such as relational transitivity choices ("her first language is Italian"), the marking of simple additive conjunction relationships ("one sport is indoor and one sport is outdoor"), a lack of interclausal linking, and simple present tense choices (Christie et al., 1989). Many of these properties are also seen in the following segment of descriptive discourse from a split information task involving four interlocutors (S5-S8) from the present study.

S7 the men's symbol the men's toilet symbol is a circle?

S8 yeah

S7 then under the circle is a cross under the circle

S5 under?

yeah is a cross yeah

S $8 \mathrm{~mm}$

S6 $[$ yep so

S7 $\quad$ ok yes (laugh) no (laugh) you are wrong is alright yeah circle and then a tring-angle

S8 yeah, triangle

S6 $\mathrm{mmm}$

S7 tring-angle

S5 triangle?

S8 [ yeah I got it (laugh) women's

S7 yeah no its a women, women, yeah

S6 triangle is man /? no/? women/? and ah...

In shared information tasks on the other hand the purpose is usually to discuss an issue. to reason or persuade in the process of working towards consensus on a ranking of items or a solution to a problem. The discourse is characterized by features of an explanatory or persuasive genre. This genre includes frequent use of textual and interpersonal themes ( $I$ think patient E because of her medical suitability), transitivity marking mental processes (I think, I disagree), use of simple present, simple past and past perfect tense choices and the likelihood of greater use of consequential conjunctive marking (so, if $)$. The following extracts from a shared information task involving four interlocutors display many of these properties.

S6 so $\mathrm{mm}$, if so, why do you, do you think $\mathrm{E}$ first the F?

S7 huh?

S8 at ah F?

S6 $\mathrm{mm}$

S7 I think the- the- the- personal characters [ is not very good

S6

S7

S8 mmm $\mathrm{mmm}$ because ah, he's a criminal record $[$ for the fraud? no his job-and $\left[\begin{array}{l}\text { the age, no, no, no, this is against the law } \\ \text { yeah (laugh) }\end{array}\right.$ job but illegal job $\left.\right|_{\text {ohh (laugh) }}$ they $\left[\begin{array}{c}\text { cheat someone like this } \\ \text { and ah, and ah- }\end{array}\right.$

S3「yeah ah how about the minister of parliament here? -because this is the the important S4 person. 
S3 [ p p patient she ...usually you know usually in our country- yeah yeah

S1 [ yes u- $u$ - usually they will get some,

S1 [ some special, oh yes I know, yes, I think, ah, in here he will put the first one

S3 yes, special for the important person

S3 [yes I think but how about-? oh sec, maybe the first one is about bad condition of the first

S1 no maybe second one yeah?

The distinction between the descriptive and persuasive modes of discourse illustrates the characteristics of the language practice offered under different task conditions and provides a framework for explaining the occurrence of discourse features in task-based interaction.

\section{HYPOTHESES}

Three hypotheses were tested. In Hypothesis 1 it was hypothesized that tasks which involved interlocutors in discussion of spatial relationships whether in a shared or split information task, would elicit more use of prepositions because one of the functions of these words is to mark locative relationships. Hypothesis 2 was that a split information task involving the discussion of spatial relationships would elicit even more prepositions than the shared information task because the task required the interlocutors to check for the accurate location of various items. Hypothesis 3 was that shared information tasks would elicit more conjunctions than split information tasks and in particular, more subordinating conjunctions because of the need to argue a case which involved marking relationships such as cause and effect, condition, result and purpose.

\section{DATA COLLECTION}

The study is based on an analysis of transcripts of about 4 hours of recorded interaction produced by two groups, each consisting of four adult learners of English as a second language at the upper intermediate level who were participants in a pre-university level English proficiency course. The transcription produced a corpus of almost 29,000 words.

Each of the two groups of learners undertook four different communicative tasks with the time taken to complete the tasks ranging from 20 to 36 minutes. The tasks included two shared and two split information tasks. One of each of these task types involved a topic describing an ethical dilemma pertaining to a medical situation, and the other the layout of a zoo. The four tasks were as follows:

Task 1 involved shared information about a medical dilemma. The learners were required to discuss and reach consensus on the order of priority of a list of critically ill patients for receiving heart surgery.

In Task 2 involving shared information about the layout of a zoo, the learners were required to reach consensus through discussion on the most suitable rearrangement of the zoo, given a number of problems arising from new developments.

Task 3 involved split information about a medical dilemma. The personal details of a number of medical patients as well as a series of criteria for selecting the most suitable 
patient for surgery were divided equally among the learners who were required to exchange this information, and use it to work out which patient would be selected for surgery.

In Task 4, involving split information about the layout of a zoo, each learner was provided with an incomplete version of the layout from which they were required to exchange information in order to complete it.

\section{DATA ANALYSIS}

The Oxford Concordance Programme (Hockey and Martin, 1988) was used to generate words counts, type token ratios and collocational information from the transcripts used in the study. The programme made no distinction between the various functions of a particular word and so for the purposes of analysis a second step was necessary in which the use of items as prepositions or conjunctions was distinguished from their other grammatical functions. This was particularly important for words such as to for which 162 occurrences $(61 \%)$ were as adverbial particles and infinitives, and about which was used 51 times $(53 \%)$ as a phrasal item such as How about...?. Distinctions were also necessary for certain conjunctions such as and which joined nominals rather than clauses 222 times $(34 \%)$ and so which was used as a pro-form in the phrase $I$ think so 39 times (12\%). In all these cases, items which did not function as either prepositions or conjunctions were excluded from the data. A small number of performance errors and ungrammatical uses of items were not excluded from the data. Adjustments for different functions of items were not made for Tables 3 and 4 where the data from this study is compared with unadjusted data from the London-Lund corpus (LLC) of spoken English and the Lancaster-Oslo-Bergen (LOB) corpus of written English.

\section{RESULTS}

Statistical analyses of differences in the occurrence of items in the task types were performed using a non-parametric test, the Page Test for Ordered Alternatives (Siegel and Castellan, 1988).

In line with the prediction in Hypothesis 1, prepositions made up a larger proportion of the words produced in discussion of the zoo topic than in the medical topic whether in a split or shared task. When the percentages in Table 1 for the topically similar tasks are combined, prepositions made up 5.8\% of words in the tasks based on a zoo topic but only $3.1 \%$ of words in the tasks based on a medical topic. These differences were significant at the $p<0.05$ level $\left(L_{2.4}=58\right)$.

Hypothesis 2 was also supported in that the split information task based on a zoo topic had a significantly higher proportion of prepositions in the text $(7.36 \%)$ than the shared information task based on the zoo topic $(4.26 \%)$. These differences were significant at the $p<0.05$ level $\left(L_{2.4}=58\right)$.

Hypothesis 3 predicted that conjunctions would be used more in shared tasks than in split tasks. This hypothesis was confirmed by the data. Table 2 shows that conjunctions made up between $5.39 \%$ and $6.24 \%$ of the data in the shared tasks and only between 
$2.79 \%$ and $3.73 \%$ in the split tasks. These differences were significant at the $p<0.05$ level $\left(L_{2.4}=58\right)$.

\section{COMPARISONS WITH NATIVE SPEAKER DATA}

The number of prepositions produced by the second language learners as shown in Table 1 ranged between $3.07 \%$ and $7.36 \%$ of the total words produced. This is much lower

Table 1. The occurrence of prepositions in texts produced by second language learners

\begin{tabular}{|c|c|c|c|c|}
\hline \multirow[b]{2}{*}{ Prepositions } & \multicolumn{4}{|c|}{ Tasks } \\
\hline & Medical shared & Zoo shared & Medical split & Zoo split \\
\hline about & 17 & 13 & 10 & 6 \\
\hline above & - & - & 5 & 33 \\
\hline across & - & - & - & 1 \\
\hline after & 3 & - & 1 & 4 \\
\hline around & - & 7 & - & 3 \\
\hline at & 3 & 4 & 9 & 3 \\
\hline before & 5 & - & 1 & - \\
\hline behind & - & - & - & 2 \\
\hline below & - & - & 10 & - \\
\hline beside & - & 3 & - & 19 \\
\hline between & 4 & 1 & 17 & 49 \\
\hline by & - & 3 & 1 & - \\
\hline for & 21 & 36 & 20 & 14 \\
\hline from & 1 & 19 & 3 & 8 \\
\hline in & 41 & 83 & 33 & 101 \\
\hline inside & - & 2 & 9 & 54 \\
\hline into & - & - & 1 & 2 \\
\hline near & - & 29 & -. & 37 \\
\hline next & - & 16 & - & 10 \\
\hline of & 26 & 43 & 19 & 74 \\
\hline on & 7 & 15 & 2 & 147 \\
\hline opposite & - & 5 & - & 4 \\
\hline outside & - & - & 12 & 24 \\
\hline over & - & 4 & 2 & - \\
\hline through & - & - & 1 & - \\
\hline to & 3 & 57 & 11 & 10 \\
\hline under & - & - & 15 & 61 \\
\hline underneath & - & - & - & 1 \\
\hline up & - & - & - & 2 \\
\hline with & 3 & 18 & 2 & 10 \\
\hline within & l & - & - & l \\
\hline without & - & 1 & 1 & 1 \\
\hline $\begin{array}{l}\text { Total number of } \\
\text { preposition tokens }\end{array}$ & 135 & 359 & 185 & 681 \\
\hline $\begin{array}{l}\text { Total number of } \\
\text { words in the } \\
\text { corpus }\end{array}$ & 4263 & 8422 & 6036 & 9248 \\
\hline $\begin{array}{l}\text { Number of } \\
\text { different words in } \\
\text { the corpus }\end{array}$ & 417 & 574 & 458 & 487 \\
\hline $\begin{array}{l}\text { Prepositions as a } \\
\text { percentage of the } \\
\text { corpus }\end{array}$ & 3.17 & 4.26 & 3.07 & 7.36 \\
\hline
\end{tabular}


Table 2. A comparison of the occurrence of conjunctions in texts produced by second language learners

\begin{tabular}{|c|c|c|c|c|}
\hline \multirow[b]{2}{*}{ Conjunctions } & \multicolumn{4}{|c|}{ Tasks } \\
\hline & Medical shared & Zoo shared & Medical split & Zoo split \\
\hline although & 1 & - & - & - \\
\hline and & 60 & 116 & 90 & 158 \\
\hline because & 47 & 76 & 17 & 5 \\
\hline but & 41 & 51 & 26 & 20 \\
\hline either & - & 2 & -- & \\
\hline if & 33 & 38 & 17 & 2 \\
\hline or & 26 & 43 & 21 & 22 \\
\hline otherwise & - & 2 & 1 & - \\
\hline so & 57 & 126 & 53 & 51 \\
\hline though & I & - & - & - \\
\hline $\begin{array}{l}\text { Total } \\
\text { conjunction } \\
\text { tokens }\end{array}$ & 266 & 454 & 225 & 258 \\
\hline $\begin{array}{l}\text { Total number } \\
\text { of words in the } \\
\text { corpus }\end{array}$ & 4263 & 8422 & 6036 & 9248 \\
\hline $\begin{array}{l}\text { Number of } \\
\text { different words } \\
\text { in the corpus }\end{array}$ & 417 & 574 & 458 & 487 \\
\hline $\begin{array}{l}\text { Conjunctions } \\
\text { as a percentage } \\
\text { of the corpus }\end{array}$ & 6.24 & 5.39 & 3.73 & 2.79 \\
\hline
\end{tabular}

than would be expected in text produced by adult native speakers of English. In both of the major available representative corpora of spoken and written British English currently available, prepositions make up between $12.4 \%$ and $13.9 \%$ of each corpus. This difference is shown in Table 3 which compares prepositions as a proportion of the total words in the two kinds of task types in this study with two large corpora of English.

The London-Lund corpus of spoken British English is the largest corpus of spoken English currently available for analysis. It consists of samples of spoken English from a wide variety of contexts including interactive discourse, totalling 435,000 words. The Lancaster-Oslo-Bergen corpus is a representative sample of British written English totalling one million words of text collected from many genres. While comparing second language learners' interactive discourse on specific tasks against these two corpora is not comparing like with like (and we would certainly not wish to base a case on a comparison of learners' spoken discourse alongside a written corpus), it is nevertheless worth noting that both split and shared tasks as carried out by second language learners produced less than half of the proportion of prepositions produced by native speakers whether in spoken or written contexts. That split tasks based on a locative topic produced such a low proportion of prepositions in comparison with the native speaker data is particularly surprising given the need to use phrases such as between the ... and next to... to locate items in relation to other items in these tasks. While our prediction would have been that this type of activity would skew the proportions the other way, generating proportionally more prepositions in the learner data, in fact this was not so. On the contrary, the comparisons for prepositions lend support to the notion that second 
language learners tend to omit function words. However, the same phenomenon does not hold in the data for conjunctions. Table 4, which records the occurrence of certain conjunctions in the texts produced by the second language learners, set alongside the relative proportion of these conjunctions in the LLC and LOB corpora, shows striking similarities. The percentage of conjunctions in the combined split and shared information

Table 3. A comparison of the occurrence of prepositions and particles produced by second language learners and native speakers of English

\begin{tabular}{|c|c|c|c|c|c|c|c|c|}
\hline \multirow[b]{2}{*}{ Prepositions } & \multicolumn{4}{|c|}{ Non-native speaker corpora } & \multicolumn{4}{|c|}{ Native speaker corpora } \\
\hline & Shared* & $\%$ & Split* & $11 / \%$ & LLC $^{*}$ & $11 / \%$ & $\mathrm{LOB}^{\dagger}$ & $1 \%$ \\
\hline about & 62 & 0.489 & 35 & 0.229 & 2043 & 0.470 & 1900 & 0.190 \\
\hline above & 0 & 0 & 38 & 0.249 & 32 & 0.007 & 297 & 0.030 \\
\hline across & 0 & 0 & 1 & 0.007 & 99 & 0.023 & 265 & 0.027 \\
\hline after & 4 & 0.032 & 5 & 0.033 & 432 & 0.099 & 1162 & 0.116 \\
\hline around & 7 & 0.055 & 3 & 0.020 & 166 & 0.038 & 245 & 0.025 \\
\hline at & 7 & 0.055 & 12 & 0.079 & 2649 & 0.609 & 6048 & 0.605 \\
\hline before & 8 & 0.063 & 2 & 0.013 & 423 & 0.097 & 1059 & 0.106 \\
\hline behind & 0 & 0 & 2 & 0.013 & 115 & 0.026 & 292 & 0.029 \\
\hline below & 0 & 0 & 10 & 0.065 & 28 & 0.006 & 150 & 0.015 \\
\hline beside & 2 & 0.016 & 19 & 0.124 & 18 & 0.004 & 90 & 0.009 \\
\hline between & 5 & 0.039 & 66 & 0.432 & 208 & 0.048 & 867 & 0.087 \\
\hline by & 3 & 0.024 & 1 & 0.007 & 1261 & 0.290 & 5836 & 0.584 \\
\hline for & 57 & 0.450 & 34 & 0.225 & 3063 & 0.704 & 9307 & 0.931 \\
\hline from & 20 & 0.158 & 11 & 0.072 & 1498 & 0.344 & 4693 & 0.469 \\
\hline in & 124 & 0.978 & 134 & 0.877 & 7929 & 1.823 & 21,356 & 2.136 \\
\hline inside & 2 & 0.016 & 63 & 0.412 & 76 & 0.017 & 138 & 0.014 \\
\hline into & 0 & 0 & 3 & 0.020 & 619 & 0.142 & 1658 & 0.166 \\
\hline near & 29 & 0.229 & 37 & 0.242 & 84 & 0.019 & 223 & 0.023 \\
\hline next & 5 & 0.039 & 35 & 0.229 & 241 & 0.055 & 416 & 0.042 \\
\hline of & 23 & 0.181 & 93 & 0.608 & 11,309 & 2.600 & 35,809 & 3.581 \\
\hline on & 69 & 0.544 & 149 & 0.975 & 3596 & 0.827 & 7052 & 0.705 \\
\hline opposite & 22 & 0.173 & 4 & 0.026 & 25 & 0.006 & 88 & 0.009 \\
\hline outside & 0 & 0 & 36 & 0.236 & 109 & 0.025 & 235 & 0.024 \\
\hline over & 4 & 0.032 & 2 & 0.013 & 506 & 0.116 & 1334 & 0.133 \\
\hline through & 0 & 0 & 1 & 0.007 & 325 & 0.075 & 776 & 0.078 \\
\hline to & 184 & 1.451 & 81 & 0.530 & 12,681 & 2.915 & 26,907 & 2.691 \\
\hline under & 0 & 0 & 76 & 0.497 & 183 & 0.042 & 669 & 0.067 \\
\hline underneath & 0 & 0 & 1 & 0.007 & 14 & 0.003 & 11 & 0.001 \\
\hline up & 5 & 0.039 & 2 & 0.013 & 1357 & 0.312 & 1975 & 0.198 \\
\hline with & 21 & 0.166 & 12 & 0.079 & 2404 & 0.553 & 7196 & 0.720 \\
\hline within & 1 & 0.008 & 1 & 0.007 & 130 & 0.030 & 345 & 0.035 \\
\hline without & 1 & 0.008 & 2 & 0.013 & 145 & 0.033 & 665 & 0.067 \\
\hline $\begin{array}{l}\text { Total } \\
\text { number of } \\
\text { prepositions } \\
\text { and particles } \\
\text { tokens }\end{array}$ & 665 & & 971 & & 53,768 & & 138,794 & \\
\hline $\begin{array}{l}\text { Number of } \\
\text { words in the } \\
\text { corpus }\end{array}$ & \multicolumn{2}{|c|}{12,685} & \multicolumn{2}{|c|}{15,284} & \multicolumn{2}{|c|}{435,000} & \multicolumn{2}{|c|}{$1,000,000$} \\
\hline $\begin{array}{l}\text { Prepositions } \\
\text { and particles } \\
\text { as a } \\
\text { percentage } \\
\text { of the corpus }\end{array}$ & \multicolumn{2}{|c|}{5.24} & \multicolumn{2}{|c|}{6.35} & \multicolumn{2}{|c|}{12.36} & \multicolumn{2}{|c|}{13.88} \\
\hline
\end{tabular}

*Spoken English. 'written English. 
Table 4. A comparison of the occurrence of conjunctions produced by second language learners and native speakers of English

\begin{tabular}{|c|c|c|c|c|c|c|c|c|}
\hline \multirow[b]{2}{*}{ Prepositions } & \multicolumn{4}{|c|}{ Non-native speaker corpora } & \multicolumn{4}{|c|}{ Native speaker corpora } \\
\hline & Shared* & $11 / 4$ & Split* & $11 \%$ & LLC $^{*}$ & $1 / 11$ & $\mathrm{LOB}^{+}$ & $1 / 11$ \\
\hline although & 1 & 0.008 & 0 & - & 105 & 0.024 & 384 & 0.038 \\
\hline and & 231 & 1.821 & 424 & 2.774 & 14.019 & 3.223 & 27,934 & 2.793 \\
\hline because & 123 & 0.970 & 22 & 0.144 & 1360 & 0.313 & 776 & 0.078 \\
\hline but & 92 & 0.725 & 46 & 0.301 & 3830 & 0.880 & 4961 & 0.496 \\
\hline either & 2 & 0.016 & 0 & - & 138 & 0.032 & 301 & 0.030 \\
\hline if & 71 & 0.560 & 19 & 0.124 & 1956 & 0.450 & 2479 & 0.248 \\
\hline or & 69 & 0.544 & 43 & 0.281 & 1884 & 0.433 & 3808 & 0.381 \\
\hline otherwise & 2 & 0.016 & 1 & 0.006 & 51 & 0.012 & 91 & 0.009 \\
\hline so & 217 & 1.716 & 109 & 0.713 & 2514 & 0.578 & 2461 & 0.246 \\
\hline though & 1 & 0.008 & 0 & - & 213 & 0.049 & 622 & 0.062 \\
\hline $\begin{array}{l}\text { Total } \\
\text { number of } \\
\text { conjunction } \\
\text { tokens }\end{array}$ & 809 & & 664 & & 26.070 & & 43.817 & \\
\hline $\begin{array}{l}\text { Number of } \\
\text { words in the } \\
\text { corpus }\end{array}$ & \multicolumn{2}{|c|}{12,685} & \multicolumn{2}{|c|}{15.284} & \multicolumn{2}{|c|}{435,000} & \multicolumn{2}{|c|}{$1,000,000$} \\
\hline $\begin{array}{l}\text { Conjunctions } \\
\text { as a } \\
\text { percentage } \\
\text { of the corpus }\end{array}$ & \multicolumn{2}{|c|}{6.38} & \multicolumn{2}{|c|}{4.34} & \multicolumn{2}{|c|}{5.99} & \multicolumn{2}{|c|}{4.38} \\
\hline
\end{tabular}

*Spoken English, ${ }^{\dagger}$ written English.

tasks in the second language learners' corpus is $5.3 \%$ of the total number of words in the corpus, which is quite comparable to the proportions in LLC $(6.4 \%)$ and LOB $(4.3 \%)$.

\section{DISCUSSION}

The use of these 45 prepositions and conjunctions which account for about $11 \%$ of all the words produced by the second language learners raises the question of why adult second language learners in the study used prepositions much less than native speakers of English typically do, but certain conjunctions very much more. The answer could be an artefact of the particular research situation. On the other hand, it could be that the answer to this question may be found in the role of these two word classes. Although, as Matthews (1981: p. 181) suggests, prepositions and conjunctions can have similar connective functions making them sometimes hard to distinguish, it is the case that prepositions generally operate at the phrasal level, linking individual lexemes to form prepositional phrases or marking particular semantic relationships between nouns or noun phrases. Thus, the thing in the box is not the same as the thing near the box. On the other hand, rather than linking lexical entities, conjunctions operate at the level of propositional semantics, linking clauses or sentences (Givón, 1990a).

From the earliest stages of first language acquisition, it is the proposition which is the unit of expression. Even at the one-word utterance level of development, the child's 
speech can be characterized as being holophrastic (de Laguna, 1927) consisting fundamentally of one-word propositions. These function as comment or predicates with the arguments normally associated with the proposition often being left unmarked or unexpressed. Thus the child who says up might be interpreted as intending I want to get up on to the chair or What I want is beyond my reach.

Adult users of English similarly do not always mark all parts of propositions in spoken discourse (e.g. Ready? - uttered without subject or verb). Sometimes relations between propositions are unmarked, as for example when causation is expressed through the juxtaposition of two propositions with no subordinating conjunction such as because.

Pinker (1984), in a review of first language acquisition literature, shows that prepositions are acquired late, after content word categories. In adult native speaker English, prepositions typically make up between $10 \%$ and about $13 \%$ of all the words in spoken or written texts (e.g. see Altenberg, 1990). As Givón (1990b) has argued, just as early first language acquisition is of the lexicon but without morpho-syntax, so there is a tendency for adult second language learner acquisition to adopt and remain at this lexical nongrammatical mode. We would thus expect there to be fewer prepositions and conjunctions in our second language learners' corpus. But why are there more conjunctions, especially in the shared information tasks? Conjunctions mark the relationships between propositions, which might be viewed as fundamental expression units of language. The evidence of the data suggests that second language learners show, through marking interpropositional relationships, that this is the natural mode of expression for them as adult second language learners experienced in reasoning in their first language.

However, it is the difference between the use of conjunctions in the shared and split information tasks which we believe to be of particular interest. As Table 4 shows, with the exception of the use of and, the "shared" corpus uses proportionately more conjunctions than the split corpus in every case, and in most cases proportionately more than in the native speaker spoken and written corpora. Shared information tasks involve interlocutors in having to argue a case on the basis of information they share rather than checking on the accuracy of information held by other interlocutors as is often the case with split information tasks. It is this reasoning or argumentation that requires conjunctions to mark the relationships between propositions. Thus tasks which call for reasoning in the second language bring out the marking of these relationships in a way not evident in their use of prepositions, the markers of intra-propositional relationships, even when the task (e.g. the zoo plan) calls for locative marking. In Tables 2 and 4, if the coordinating conjunction and is excluded, then the huge disparity between conjunction use in shared and split information tasks is accentuated even further.

It is thus suggested that for both cognitive reasons (a need to reason, persuade, or argue) and pragmatic reasons (we communicate in propositions), adult second language learners may behave as if the expression of propositions and the relationships between them has a higher priority than the marking of relationships between concepts. Shared information tasks of the kind used in this study appear to encourage the generation, expression and marking of inter-propositional relationships. Split information tasks in this study produced slightly more talk (although a similar number of different words) when 
compared with shared information tasks. But the shared tasks resulted generally in more inter-propositional relationships being marked and a different kind of talk in which argumentation marked particularly by means of subordination is demanded by the nature of the task.

\section{IMPLICATIONS FOR SECOND LANGUAGE LEARNING AND TEACHING}

The results of this study suggest that language learning tasks can be selected to influence not only the occurrence of more or less talk and negotiation, but also particular linguistic features and structures. Whereas one of the well-attested advantages of split information tasks is that they encourage more interaction and negotiation than shared information tasks, the latter can be used to encourage reasoning, argumentation, conjecture and other pragmatic behaviours with consequent linguistic marking. The quality of these behaviours, whether measured by well-formedness, grammatical complexity, richness of vocabulary or sociolinguistic appropriateness is surely relevant for learning.

The results also suggest that further work is needed on how other groupings of interlocutors perform on the different task types to see whether the differences in the linguistic marking of inter-propositional and intra-propositional relationships noted in the present study are maintained. In particular, we would wish to see whether the performance of groups of second language learners is different from groups of native speakers of English or of mixed native and non-native speaker interlocutors.

The pedagogical implications of choosing tasks and topics to influence specific language behaviours also needs re-examination. Whether it is desirable. for example, to encourage the use of if or because to mark inter-propositional relationships which are in turn called forth by the demands of the task is a matter for consideration by those concerned with pedagogical theory as well as those concerned with classroom practice.

\section{REFERENCES}

ALTENBERG, B. (1990) Spoken English and the Dictionary. In J. Svartvik (ed.), The London-Lund Corpus of Spoken English: Description and Research (pp. 177-192) Lund: Lund University Press.

BROWN, G. (1990) Text comprehension: missing the cues. Journal of Applied Linguistics 6, 37-47.

CANDLIN, C. N. and MURPHY, D. F. (eds.) (1987) Language Learning Tasks. Englewood Cliffs NJ: Prentice-Hall.

CELCE-MURCIA, M. and LARSEN-FREEMAN, D. (1983) The Grammar Book. Rowley, MA: Newbury House CHRISTIE, F.. ROTHERY. J. and MACLEAN, R. (1989) Writing in Schools Study Guide (1989). Geelong: Deakin University Press.

COHEN, E. G. (1986) Designing Groupwork. New York: Teachers College Press.

CROOKES, G. (1986) Task Classification: a Cross-Disciplinary Review. Technical Report No. 4. Honolulu: Centre for Second Language Classroom Research. University of Hawaii at Manoa.

CROOKES, G. and GASS, S. (1993a) Tasks and Language Learning: Integrating Theory and Practice. Clevedon, PA: Multilingual Matters.

CROOKES, G. and GASS, S. (eds) (1993b) Tasks in Pedagogical Context: Integrating Theory and Practice. Clevedon, PA: Multilingual Matters. 
DE LAGUNA, G. (1927) Speech: Its Functions and Development. New Haven: Yale University Press.

DOUGHTY, C. and PICA, T. (1986) Information gap tasks: do they facilitate SLA? TESOL Quarterly 20(2), 305-325.

EGGINS, S. (1994) An Introduction to Systematic Linguistics. London: Pinter.

ELLIS, R. (1991) The interaction hypotheses: a critical evaluation. In E. Sadtono (ed.), Language Acquisition and the Second/Foreign Language Classroom (pp. 179-211). Anthology Series 29, Singapore: SEAMEO RELC.

FOTOS, S. (1993) Consciousness raising and noticing through focus on form: grammar task performance verse formal instruction. Applied Linguistics 14(4), 385-404.

FOTOS, S. and ELLIS, R. (1991) Communicating about grammar: A task-based approach. TESOL Quarterly 25, 605-628.

GASS, S. and MADDEN, C. (eds) (1985) Input in Second Language Acquisition. Rowley. MA: Newbury House.

GIVÓN, T. (1990a) Sỵtax: A Functional-Typological Introduction, Vol. 2. Amsterdam: John Benjamins.

GIVÓN, T. (1990b) National Language Learning and Organized Language Teaching. In H. Burmeister and P. L. Rounds (eds), Variability in Second Language Acquisition (pp. 61-84). Portland: University of Oregon Press.

HANCOCK. P. A. (1987) Human Factor Psychology. New York: Elsevier.

HOCKEY, S. and MARTIN, J. (1988) Micro-OCP. Oxford: Oxford University Press.

KEENAN, E. (1974) Conversational competence in children. Journal of Child Language 1, 163-183.

LONG. M. (1989) Task, group, and task-group interactions. Paper presented at the RELC Regional Seminar, Singapore, April 1989.

LONG, M. and CROOKES, G. (1991) Three approaches to task-based syllabus design. University of Hawaii Working Papers in ESL, Vol. 10, No. 1, pp. 1-36.

LOSCHKY, L. and BLEY-VROMAN, R. (1993) Grammar and task-based methodology. In G. Crooks and S. Gass (eds). Tasks and Language Learning: Integrating Theory and Practice (pp. 123-167). Clevedon, PA: Multilingual Matters

MARTIN, J. (1984) Language, register and genre. In F. Christie (ed.), Children Writing: Reader (pp, 21-29). Geelong: Deakin University Press.

MATTHEWS, P. H. (1981) Syntax. Cambridge: Cambridge University Press.

NATION, I. S. P. and THOMAS, G. I. (1988) Communication Activities. Occasional Publications No. 13. Wellington: Victoria University of Wellington.

NUNAN, D. (1989) Designing Tasks for the Communicative Classroom. Cambridge: Cambridge University Press.

NUNAN, D. (1991) Communication tasks and the language curriculum. TESOL Quarterly 25(2), 279-295.

PICA, T., HOLLIDAY, L., LEWIS, N. and MORGENTHALER, L. (1989) Comprehensible output as an outcome of linguistic demands on the learner. Studies in Second Language Acquisition 11(1), 63-90.

PICA, T., YOUNG, R. and DOUGHTY, C. (1987) The impact of interaction on comprehension. TESOL Quarterly 21(4), 737-758.

PINKER, S. (1984) Language Learnability and Language Development. Cambridge, MA: MIT Press.

PRABHU, N. (1987) Second Language Pedagogy. Oxford: Oxford University Press.

SIEGEL, S. and CASTELLAN, N. J. (1988) Nonparametric Statistics for the Behavioural Sciences, 2nd edn. New York: McGraw-Hill.

SWAIN, M. (1985) Communicative competence: some roles of comprehensible input and comprehensible output in its development. In S. Gass and C. Madden (eds), Input in Second Language Acquisition (pp. 235-253). Rowley, MA: Newbury House.

SWALES, J. (1990) Genre Analysis: English in Academic and Research Settings. Cambridge: Cambridge University Press.

UR, P. (1981) Discussions that Work. Cambridge: Cambridge University Press.

UR, P. (1988) Grammar Practice Activities. Cambridge: Cambridge University Press. 